\title{
THE COMPREHENSIVE HISTORICAL UPPER-AIR NETWORK
}

\author{
by A. Stickler, A. N. Grant, T. Ewen, T. F. Ross, R. S. Vose, J. Comeaux, P. Bessemoulin, \\ K. Jylhä, W. K. Adam, P. Jeannet, A. Nagurny, A. M. Sterin, R. Allan, \\ G. P. COMPo, T. GRIESSER, AND S. BRÖNNIMANN
}

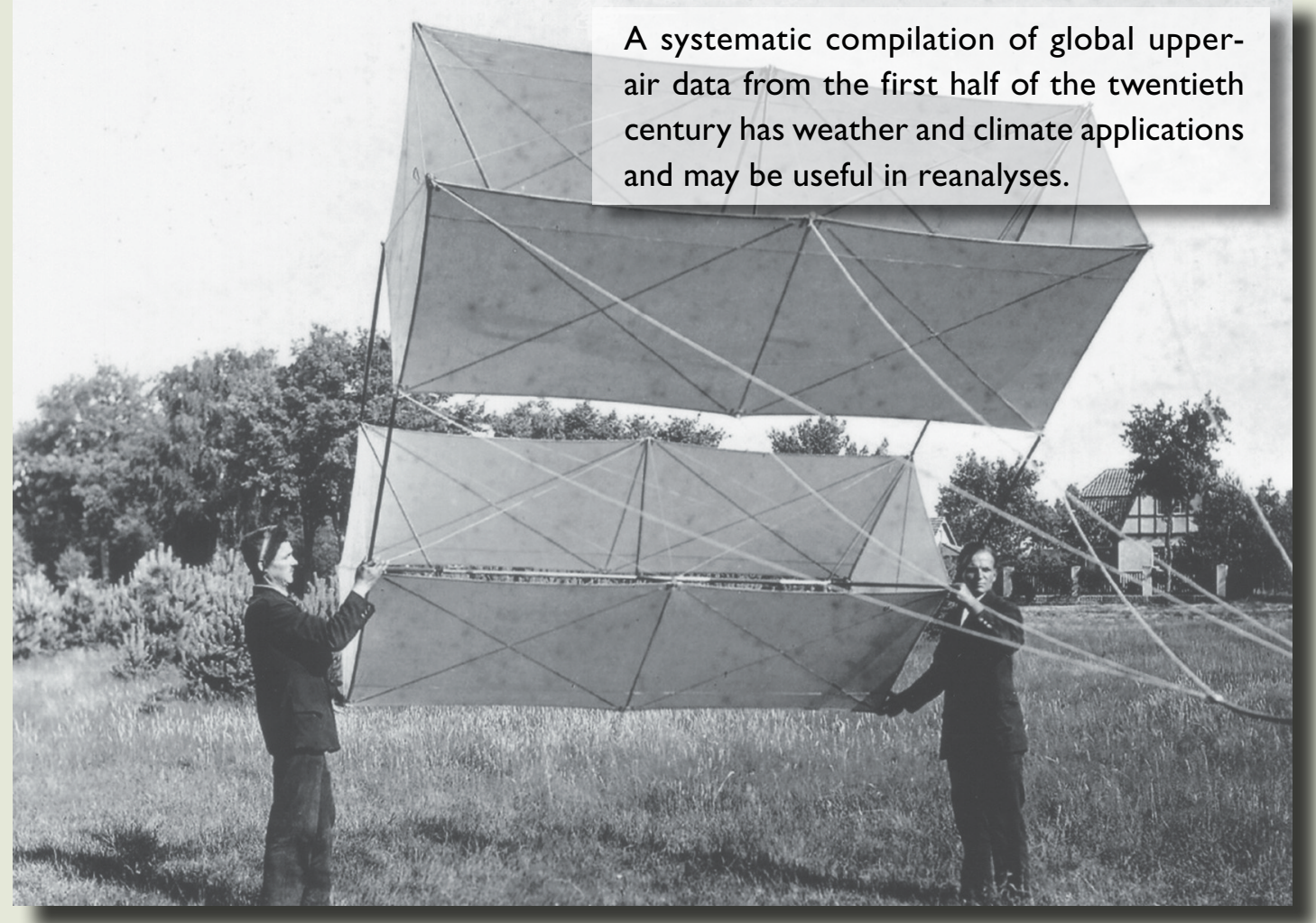

Two men launching a meteorological kite (a so-called "umbrella kite"). This type of kite amongst others was used during the first half of the twentirth century (e.g., at the observatory of Lindenberg, Germany), to obtain vertical profiles of atmospheric variables like temperature, pressure and humidity. The umbrella kite was also used during field expeditions, for launches on board ships, and as an observational platform for military air weather service and artillery during World War I. A still valid world record is connected to the umbrella kite: a maximum altitude of $9,740 \mathrm{~m}$ a.s.I. was reached during an ascent on August Ist 1919 by a combination of several such kites. (Photo courtesy of www.wetterdrachen.de.)

$\mathrm{T}$ o improve our understanding of global weather and climate variability and its change under the influence of global warming, it is vital to extend our knowledge about the atmospheric state and variability in the past. Current reanalysis datasets [the National Centers for Environmental Prediction (NCEP)-National Center for Atmospheric Research (NCAR) 50-Year Reanalysis (Kistler et al. 2001) and the 40-yr European Centre for MediumRange Weather Forecasts (ECMWF) Re-Analysis (ERA-40; Uppala et al. 2005)] provide detailed information on the atmosphere during the past 60 years. The first half of the twentieth century, however-which features some very prominent climate fluctuations such as 
the Arctic Warming from the 1920s to the 1940s (Polyakov et al. 2003; Overland et al. 2004; Grant et al. 2009b), the Midwest Dust Bowl droughts in the 1930s (Schubert et al. 2004a; Brönnimann et al. 2009a; Cook et al. 2009), the 1939-42 El Niño (Allan et al. 2003; Brönnimann et al. 2004a,b), and numerous weather extremes-is not covered by these datasets. Also, the roughly 60 years covered by the abovementioned reanalyses have proven to be too short to sample the whole range of global atmospheric variability, a shortcoming particularly important when it comes to assessing extremes.

During the past few years a number of efforts have been focusing on extending atmospheric datasets back to the early twentieth or even nineteenth century, including a reanalysis using only synoptic surface pressure and monthly sea surface temperature and sea ice data (The Twentieth-Century Reanalysis Project; see www.esrl.noaa.gov/psd/data/20thC_Rean/). The Atmospheric Circulation Reconstructions over the Earth (ACRE; see www.met-acre.org/) initiative serves as a platform for these activities. In this paper we describe another activity that is complementary to the Twentieth-Century Reanalysis, namely a compilation of a comprehensive, global, historical, upper-air dataset for use in weather and climate applications (analysis, data and model evaluation) and possible future reanalysis efforts.

The reason why current "full" reanalyses (i.e., those including upper-air data) do not reach further back than 1957 or 1948 is the general lack of quality controlled, electronically available upper-air data prior to the International Geophysical Year (IGY) 1957/58. To overcome this deficiency, a large number of historical upper-air datasets from different measurement platforms such as kites, registering balloons, aircraft, pilot balloons, and radiosondes have been digitized [e.g., in the framework of the Climate Data Modernization Program (CDMP) - see

AfFiliations: Stickler, Grant, EWen, Griesser, and BRÖNNIMANN - Institute for Atmospheric and Climate Science, ETH Zurich, Zurich, Switzerland; Ross AND Vose-NOAA National Climatic Data Center, Asheville, North Carolina; ComeauXNational Center for Atmospheric Research, Boulder, Colorado; BesSEMOULIN-Météo-France, Toulouse, France; JYLHÄ-Finnish Meteorological Institute, Helsinki, Finland; ADAM-Deutscher Wetterdienst, Meteorological Observatory, Lindenberg, Germany; JeAnNet-MeteoSwiss Aerological Station, Payerne, Switzerland; NagurnY-Arctic and Antarctic Research Institute, St. Petersburg, Russia; SterIN-RIHMI-WDC, Obninsk, Russia; Allen-Met Office Hadley Centre, Exeter, United Kingdom; Compo-University of Colorado CIRES Climate Diagnostics Center, and NOAA Earth the NOAA/National Climate Data Center (NCDC) CDMP website at www.ncdc.noaa.gov/oa/climate/ $\mathrm{cdmp} / \mathrm{cdmp} . h \mathrm{tml}$ and the International Environmental Data Rescue Organization at www.iedro.org-or at Météo-France or at ETH Zurich; Brönnimann 2003a,b; Ewen et al. 2008a] or compiled from existing archives over the past few years. Before 1948, a large fraction of the data stems from pilot balloon observations. The full dataset comprises, among other parameters, wind direction and speed, pressure, geopotential height (GPH), and temperature. However, it comes in various formats and qualities, and it is given on partly nonuniform pressure as well as geometrical altitude levels. Furthermore, up to now there has not been a serious attempt to systematically compile all the data and to rigorously assess its quality.

Here we describe a new dataset termed the Comprehensive Historical Upper-Air Network (CHUAN), which has been developed as a systematic compilation of the different sources in only three standard formats: one for the data that come on pressure levels from all platforms except radiosondes, one for the data on geometrical altitude levels, and one with four additional pressure levels for the radiosonde data. Additionally, we demonstrate the usefulness of the new dataset by showing selected examples of twentieth-century climate events that have been analyzed using the data. The full station record documentation including station name, location/elevation, time coverage, measurement platform, total number of records at the station, data source, and quality are provided online (see www. historicalupperair.org). Detailed information on the evaluation, adjustment, and quality assessment of the data can be found in the online documentation and supplement.

\section{THE NEW HISTORICAL UPPER-AIR DATA-} SET. Data sources. CHUAN has been compiled from

System Research Laboratory/Physical Sciences Division, Boulder, Colorado

A supplement to this article is available online (doi:10.1 I75/2009BAMS2852.2) CORRESPONDING AUTHOR: Dr. Alexander Stickler, Institute for Atmospheric and Climate Science, Universitätstrasse 16, ETH Zurich, CHN, CH-8092 Zurich, Switzerland

E-mail: alexander.stickler@env.ethz.ch

The abstract for this article can be found in this issue, following the table of contents.

DOI:10.1175/2009BAMS2852.I

In final form 3 December 2009

(C)2010 American Meteorological Society 
TABLE I. Number of soundings for different measurement platforms and time periods.

\begin{tabular}{|l|c|c|c|c|}
\hline \multicolumn{1}{|c|}{ Platform } & pre-1928 & 1928-37 & 1938-47 & 1948-57 \\
\hline Aircraft & 1,419 & 15,363 & 7,392 & 0 \\
\hline Kite & 29,850 & 28,501 & 495 & 0 \\
\hline Pilot balloon/registering balloon & 240,200 & $1,061,328$ & $3,794,542$ & $5,101,760$ \\
\hline Radiosonde & 0 & 1,004 & 147,099 & $2,319,339$ \\
\hline
\end{tabular}

historicalupperair.org). Besides station number, station name, source dataset, geographical position, and elevation, that listing shows the station numbers in the original dataset and, if identifiable, in the World Meteorological Organization (WMO) and/

15 different sources. These, together with information about the measurement platforms, the altitude grid used, the measured variables, and whether or not quality checks or adjustments have been applied to the respective dataset, can be found in the online documentation (see www.historicalupperair.org). The largest fraction of the data (TD52/53, TD54, TD-6201, CARDS542; see also Eskridge et al. 1995) had already been digitized in earlier years and was mostly stored on magnetic tape decks. Other parts of the data have been digitized more recently at the University of Arizona, at NOAA-NCDC in the framework of the CDMP (Dupigny-Giroux et al. 2007), at the Arctic and Antarctic Research Institute (AARI; St. Petersburg, Russia), and at the Institute for Atmospheric and Climate Science (ETH Zurich, Switzerland). The historical radiosonde data were supplemented up to the present with data from the International Global Radiosonde Archive (IGRA; Durre et al. 2006; see Grant et al. 2009a for details on the merging). Note, however, that we have not systematically compiled data series starting after 1957 but have merely extended the radiosonde records with corresponding IGRA data after 1957.

As can be seen from Table 1, the largest portion of the data consists of pilot balloon and radiosonde measurements. In the original data sources the pilot balloon data are given predominantly on geometrical altitude levels above mean sea level, but some observations are given on levels above ground level or on pressure levels. The radiosonde data are given solely on pressure $(p)$ levels whereas the kite, aircraft, and registering balloon data are either on pressure or geometrical altitude levels. The majority of the data, including all radiosonde measurements and $>98 \%$ of the number of pilot balloon archives, has been evaluated, with some pilot balloon, kite, aircraft, and registering balloon data on $p$ levels remaining to be checked for quality.

Detailed documentation. Much more detailed information on each record contained in CHUAN can be found in the detailed station list online ( $w w w$. or Weather Bureau-Army-Navy (WBAN) system, as well as whether the record has been merged with other records. The latter information is also given more precisely for the radiosonde data described in Grant et al. (2009a). Records have only been merged whenever identical WMO indices and/or WBAN numbers (as listed in WMO Publication 9 Volume A, available at ftp://ftp.wmo.int/wmo-ddbs/, and at ftp://ftp.ncdc. noaa.gov/pub/data/inventories/WBAN.TXT) could be identified and the measurement platform was the same. Nevertheless, potential further merging partners in the surroundings of each station, identified as great circle distances $<25 \mathrm{~km}$ calculated from the geographical coordinates, are also listed. Additionally, the covered period, the total number of ascents (number of covered months in the case of the Monthly Weather Review datasets; i.e., monthly mean data extracted from the correspondent publication), the measurement platform(s), and information on the evaluation or adjustment processes are included.

Reformatting of the data. CHUAN data have been reformatted into three simple ASCII formats, one each for pressure level and geometrical altitude level data, and one with four additional pressure levels for the radiosonde data. The pressure level data have been incorporated without any interpolation and are given on surfaces of 1000, 950, 925, 900, $850,800,750,700,650,600,550,500,450,400,350$, $300,250,200,175,150,125,100$, and $50 \mathrm{hPa}$. For the radiosonde data, additional levels are available at 70 , 30, 20, and $10 \mathrm{hPa}$.

The data on geometrical altitude levels have been mapped onto a common, fixed-altitude grid relative to the mean sea level with a relatively high vertical resolution: $0 \mathrm{~m}$ above ground level (AGL), 150, 250, $300,500,750,1000,1250, \ldots ., 15,750,16,000,16,250$, $16,500,17,000,18,000, \ldots, 30,000 \mathrm{~m}$ above mean sea level (MSL). This ensures that none of the datasets experiences a loss in vertical resolution. However, this also implies that the wind and temperature data originally given on altitude levels AGL (the so-called "daily" format of the NOAA CDMP data and some 


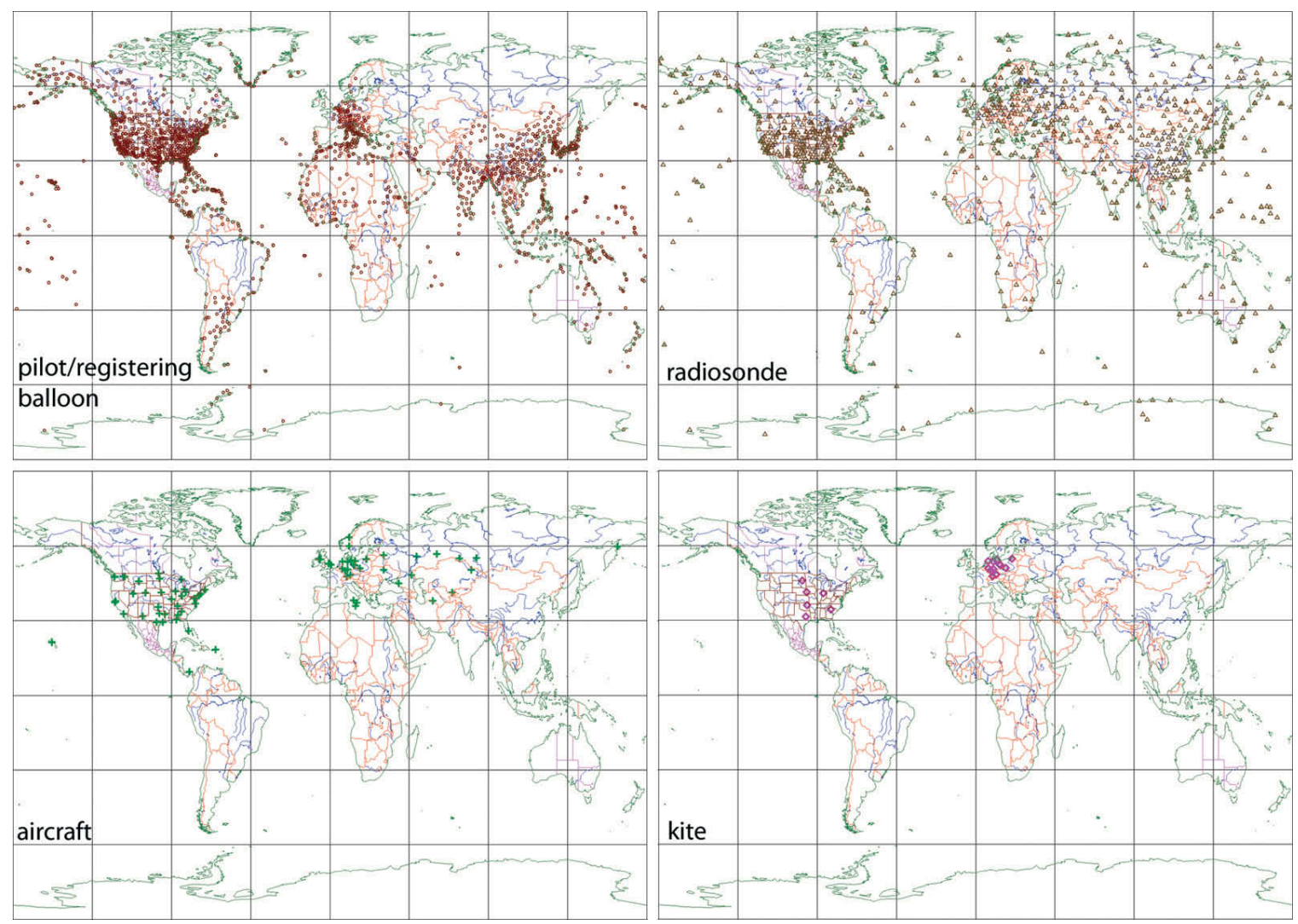

FIG. I. Maps showing the global distribution of all CHUAN upper-air stations (1902-57). For clarity, measurement platforms are presented separately in the four panels.

records of TD52/53) had to be linearly interpolated onto the new levels (indicated by flags). In general, interpolation was done only above $2000 \mathrm{~m} \mathrm{AGL}$ to prevent nonlinear effects from the atmospheric boundary layer $(\mathrm{ABL})$ or the distortion of strong gradients. In the case of the CDMP daily format data however, interpolation could be safely continued down into the ABL because of the relatively high resolution of about $200 \mathrm{~m}$.

Calculation of monthly means. Monthly means of all station records have been calculated and (with the exception of the data received from AARI) are being made available to the public on the World Wide Web (www.historicalupperair.org). To ensure an adequate number of measurements, monthly averages of temperature, pressure, or GPH have only been calculated if (for a given level and variable) at least 13 days had data or if there were no gaps of more than 7 consecutive days. In one case (early U.S. data from the Monthly Weather Review; see detailed online documentation) ascent statistics were used to flag monthly means with likely too little information. For the pilot balloon wind data a minimum of 20 days per month with measurements is required because the visual tracking of the balloons prior to the mid-1940s might introduce a systematic sampling bias (whether or not a balloon is visible depends on the weather). The radiosonde data have been supplemented with IGRA data where available (number 3286-4181) after the end of the primary source record.

Global distribution of measurements. Figure 1 displays the global distribution of the CHUAN measurement stations labeled according to the measurement platform. CHUAN incorporates a total of 3987 station records (note that this is not the same as the number of stations since different platforms are treated separately and because in some cases parts of the records from identical stations could not be merged because of quality issues and thus were kept separate in the dataset). The geographical coverage of the station network changes over time (see Fig. 2). In the pre-1928 period, only the United States, including overseas military bases, a strip from central Europe to the central Mediterranean, Japan, and New Zealand are covered by observations. In the subsequent decade, upper-air records from Alaska, Scandinavia, the Eurasian Arctic coasts, and Korea are added. Additionally, two records appear in 

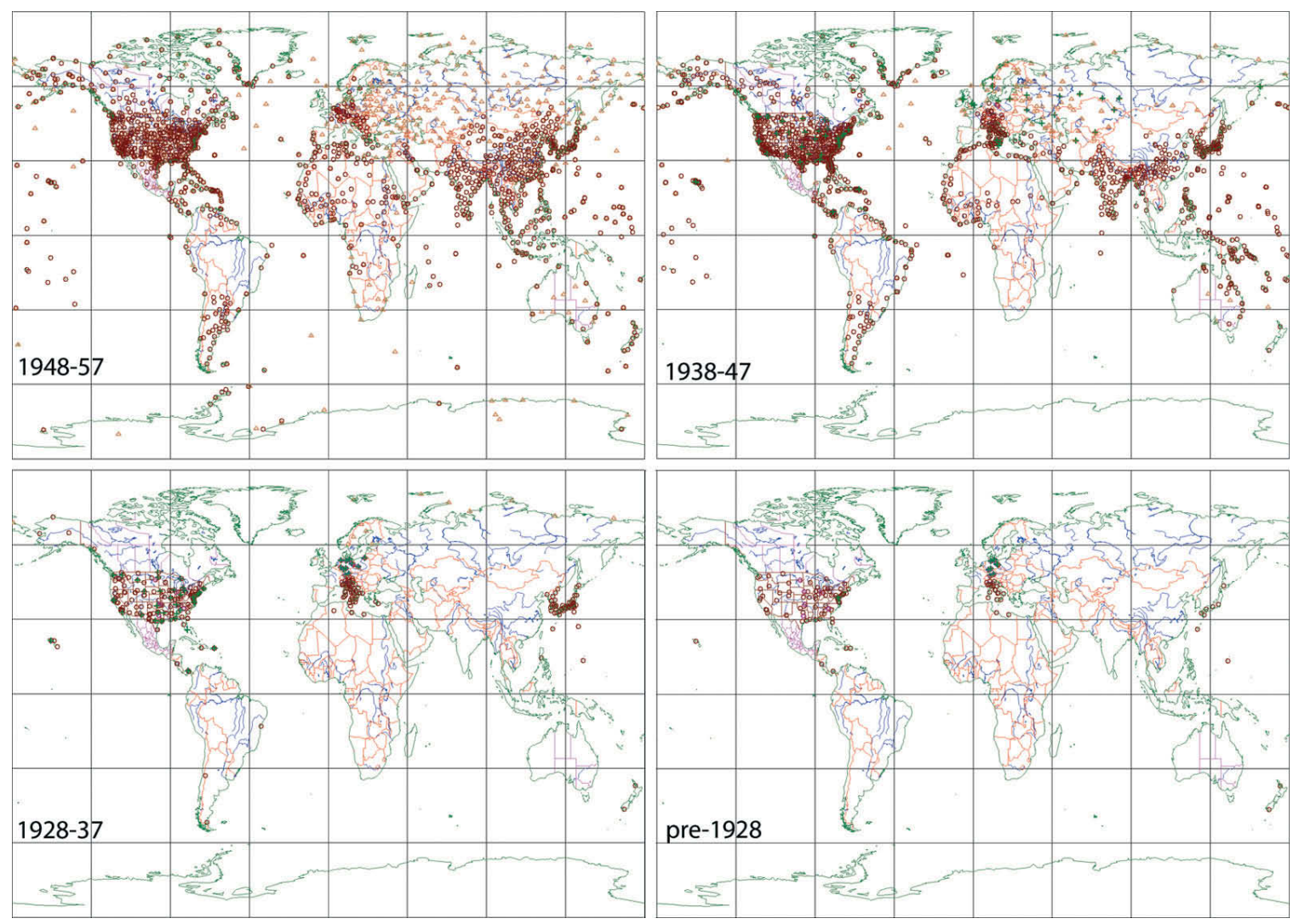

Fig. 2. Maps showing the changing density of the CHUAN upper-air station network over the decades 1948-57, 1938-47, and 1928-37, as well as the pre-1928 period.

South America. The decade $1938-47$ is characterized by a strong increase in the number of records (see also Fig. 3) and a much better global station density. Large parts of the Northern Hemisphere land masses are now covered with the exception of the Sahara, central Greenland, and parts of Siberia. The increased density of the measurement network is especially noticeable in the tropics and the Southern Hemisphere, although vast areas remain uncovered (central South America, Antarctica, central and southern Africa, and the Southern Ocean basins). During 1948-57, the trend toward better coverage continues. More records are now available for Mexico, the Canadian
Arctic, Siberia, Africa, western Australia, the Southern Hemispheric ocean basins, and Antarctica.

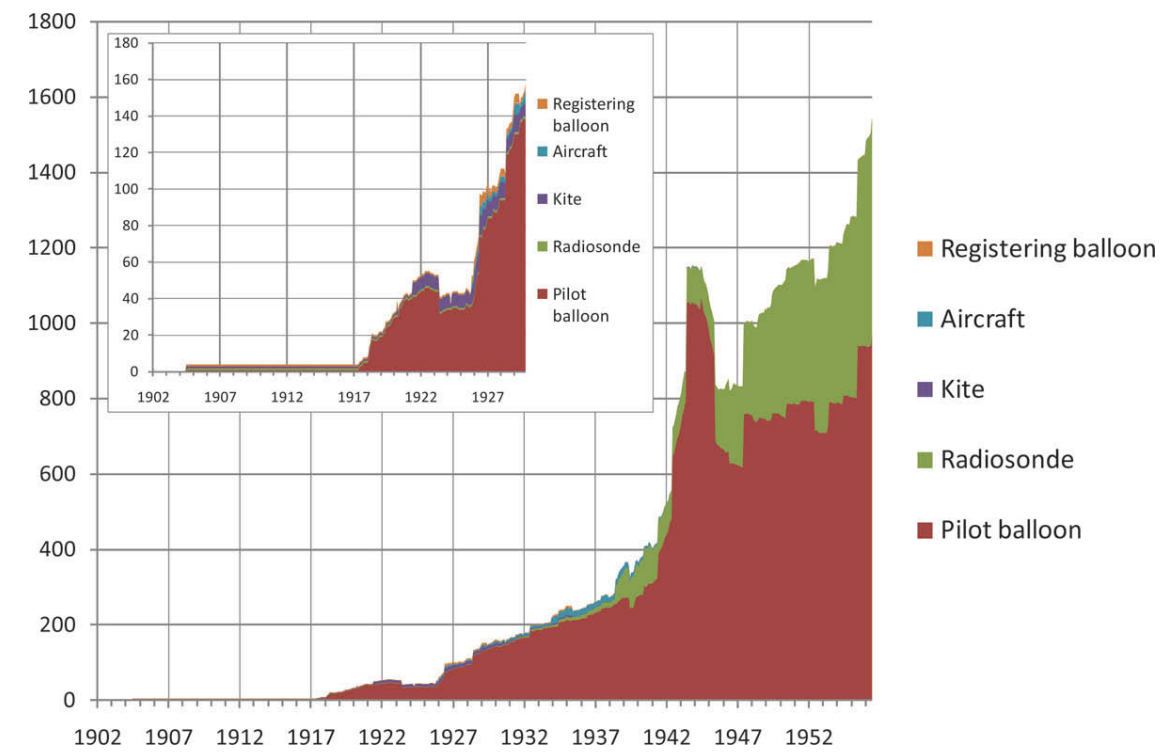

Fig. 3. Number of available records versus time. Records that have multiple measurement platforms as well as records from identical stations (with respect to the WMO station index or the NCDC's WBAN number) that have not yet been merged due to the lack of a quality assessment (see detailed station listing in the online documentation at www.historicalupperair.org) are counted separately. 
One exception is South America, where coverage decreases along the Brazilian coastline. In general, the highest station density can be found in the Northern Hemisphere, especially in the United States and the Caribbean, central and eastern Europe, the Mediterranean region, and India, China, and Japan. The lowest coverage can be distinguished over the oceans (especially over the Southern Ocean) and over the Amazon basin, parts of Africa, the Arabian Peninsula, Iran, Australia, central Greenland, and Antarctica.

Evolution of available data over time. Figure 3 shows the number of available records versus time. The total number of profiles contained in CHUAN is $\approx 16.4$ million, of which about 12.6 and 5.3 million profiles date from before 1958 and 1948, respectively. The period covered starts on 11 August 1902, when two stations in Germany (Frankfurt and Friedrichshafen) launched registering balloon ${ }^{1}$ in the framework of the "International Aerological Days," internationally coordinated one-day observational programs (Hoinka 1997). It is only in February 1905, though, that the records resume with regular upperair measurements at the observatory of Lindenberg, about $60 \mathrm{~km}$ southeast of Berlin. ${ }^{2}$ In the early period until about 1918, kite, aircraft, and registering balloon measurements dominate, with very few stations available. Between 1918 and 1928 pilot balloons became the most important contributor to upper-air information, while kites still played an important role. During the '20s and especially the ' 30 s, aircraft were a significant but not dominant contributor to the data. Additionally, during the '30s the use of radiosondes became more widespread. The second half of WWII exhibits a peak in the number of available records, especially for pilot balloons, while the number of radiosonde records shows even a slight decline during the last years of WWII relative to the late '30s/early '40s. However, this decline is followed by a large increase after WWII and a concurrent decrease in the number of pilot balloon records. The total number of upper-air records during the second half of WWII is reached again only in the mid '50s.

\footnotetext{
${ }^{1}$ Registering balloons are weather balloons carrying registering instruments without being equipped with a radio transmitter.

${ }^{2}$ The first kite and balloon ascents in Berlin were made by Aßmann from $1900 \mathrm{on}$. Starting in 1902, regular upper-air measurements were performed at the observatory in Tegel. In 1905 the observatory was transferred away from the city to Lindenberg because of the better meteorological and administrative conditions found there. The data obtained during the ascents in Tegel have not yet been digitized and processed.
}
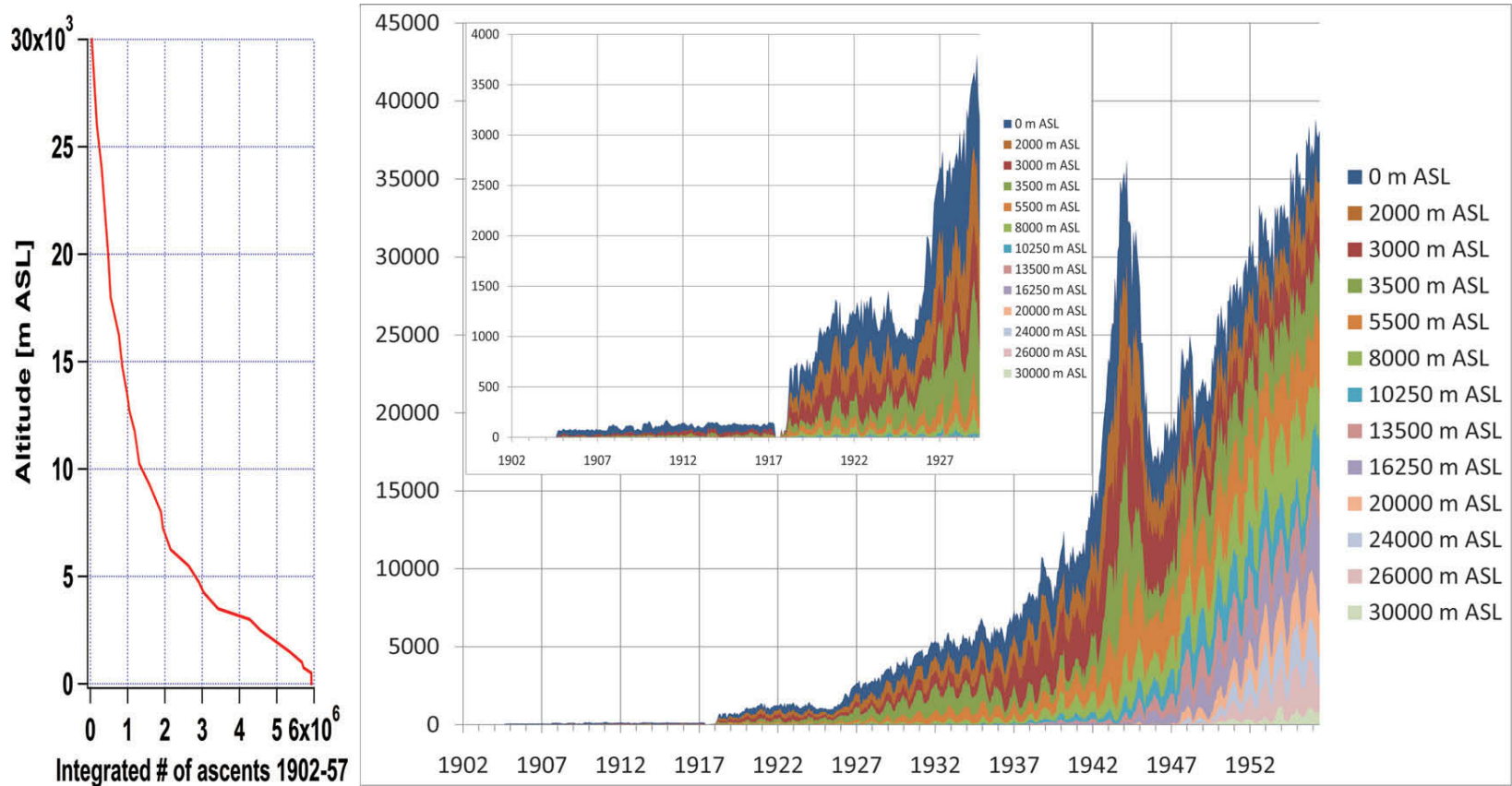

FIG. 4. (left) Vertical profile of the total number of daytime (0600-I800 LT) ascents integrated over the period 1902-56. (right) Number of daytime ascents reaching different altitude levels MSL versus time. 
Figures 4 and 5 give an impression of the vertical distribution of the data over time, broken down into daytime and nighttime observations. Time series of the number of observations on different altitude levels above mean sea level are given in the right panels of the figures. For the daytime observations (Fig. 4), the general picture looks similar to the total number of available records over time, even though the peak in the mid '40s stands out clearly. For the nighttime observations (Fig. 5) there is a clear dip around 1925, which is not seen in the daytime observations. Also, the relative number of nighttime observations is very small before about 1913. In general, the number of nighttime observations is significantly smaller than the number of daytime observations (note the different scales in both figures). However, the difference is less than about $30 \%$ from 1938 on, whereas it temporarily reaches over $50 \%$ before that time. Integrated over time (1902-56), the difference between the number of nighttime and daytime observations is not so apparent: The upper parts of the vertical profiles (above $10 \mathrm{~km} \mathrm{ASL}$; see left panels) are dominated by the radiosondes, which show practically no predominance of the number of daytime ascents relative to the number of nighttime ascents. In contrast, the lower parts of the profiles, dominated by pilot balloon measurements, exhibit a clear predominance of daytime ascents.

Furthermore, both figures reveal the annual cycle of the number of observations with maxima in boreal summer and minima in boreal winter, especially at higher levels. This might be explained by a combination of the dominance of the Northern Hemisphere in CHUAN and generally more clouds during the winter season, which hamper the tracking of pilot balloons, the dominant measurement platform in the dataset.

EXAMPLES OF USE. There is a wide range of possible applications for CHUAN. In fact the data have already been used for various applications; for instance, they have been used to derive and evaluate data products such as statistical reconstructions (Brönnimann and Luterbacher 2004; Ewen et al. 2008b; Brönnimann et al. 2009a,b; Griesser et al. 2010), to evaluate and assess reanalysis datasets (Grant et al. 2009a; Compo et al. 2006), to analyze important climate events such as the early twentiethcentury Arctic warming (Grant et al. 2009b), the "Dust Bowl" droughts (Brönnimann et al. 2009a) and the 1939-42 El Niño (Brönnimann et al. 2004a,b), and to examine the variability and trends of major indices of Northern Hemispheric circulation during the twentieth century (Brönnimann et al. 2009b). In the following we briefly summarize this work and give additional examples of applications such as a case study of a severe storm.

Evaluation of reanalyses. Grant et al. (2009a), who homogenized the radiosonde data included here and applied the physics- and station history-based
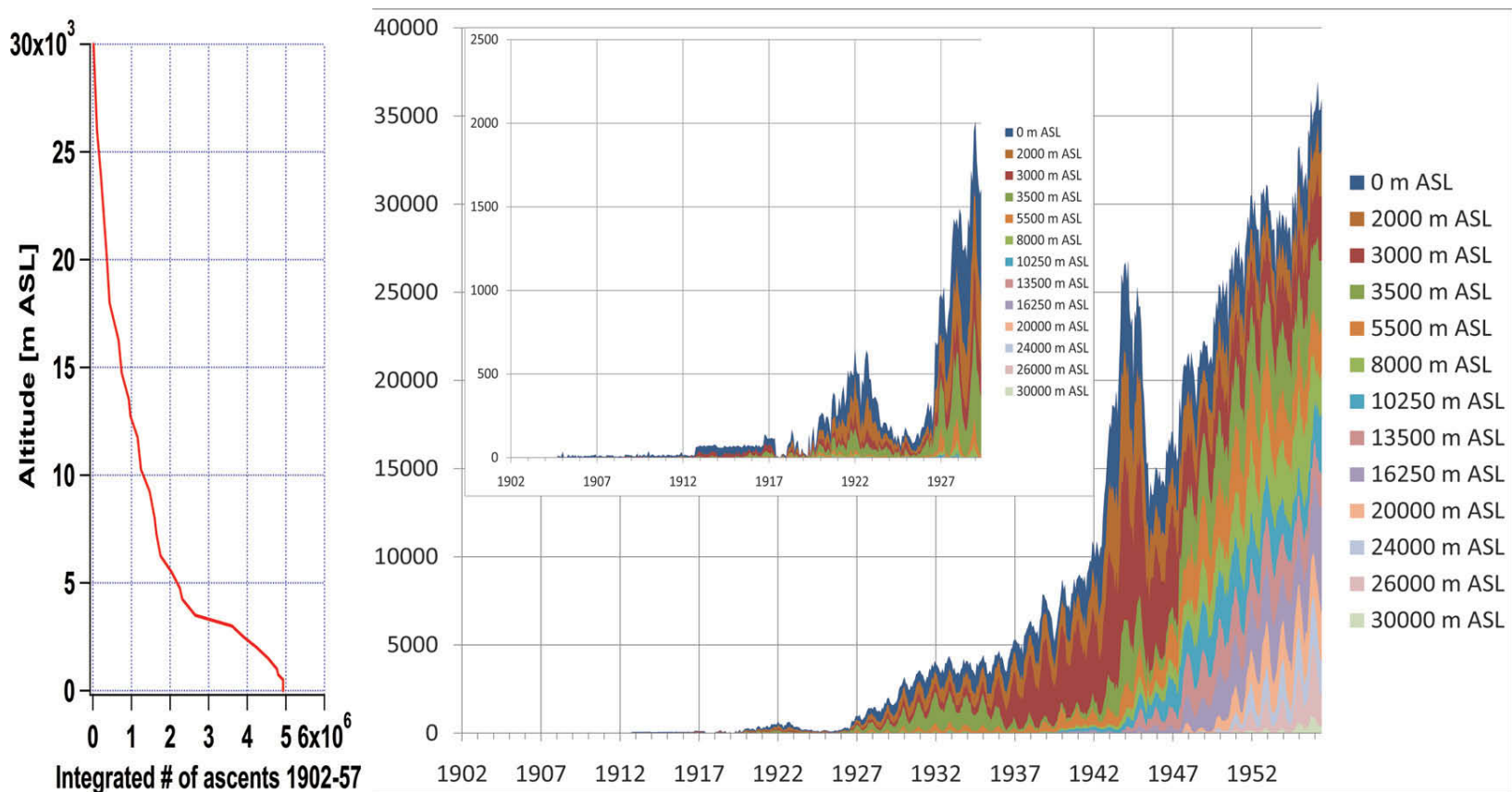

Fig. 5. (left) Vertical profile of the total number of nighttime (18-06 LT) ascents integrated over 1902-56. (right) Number of nighttime ascents reaching different altitude levels MSL vs time. 

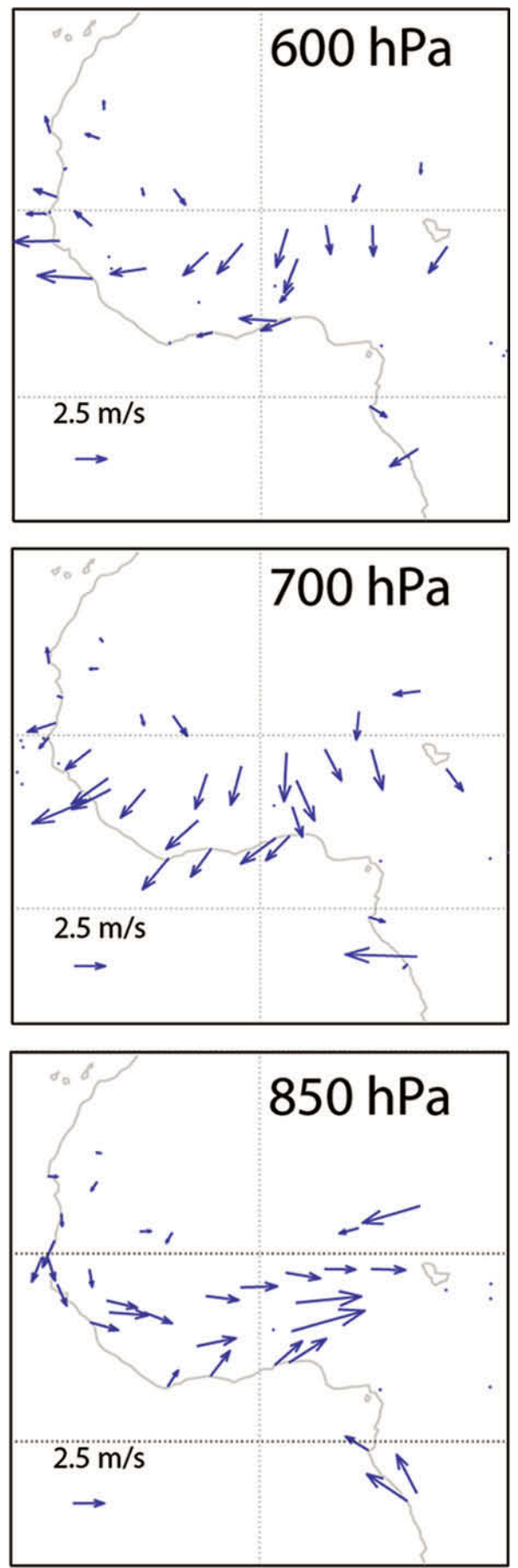

FIG. 6. Fields of the JJA mean difference of wind data from the NCEP-NCAR 50 -yr reanalysis relative to wind observations from pilot balloons and in west and central Africa for 1948-57. The mean difference has been calculated from average $U$ and $V$ wind differences between reanalysis winds and single wind observations (pilot balloon ascents) from CHUAN in a time window of $\max 2 h$ around the reanalysis times (0000, 0600, 1200, and I800 UTC). adjustments described in the online documentation and supplement, have shown that these adjustments lead to large changes and improved internal consistency of GPH as well as $T$ fields over large parts of Eurasia compared to the unadjusted data. They also demonstrated that the assimilation of these erroneous data into the NCEP-NCAR 50-year reanalysis has led to a formerly unnoticed widespread warm bias in the 1950s (their Fig. 9).

Using single-ascent pilot balloon data from CHUAN, we find strong indications that there exist significant and spatially systematic differences between the NCEP-NCAR 50-year reanalysis and wind observations over the West African monsoon region. The spatial organization of these differences, calculated with respect to observations taken inside time windows of a maximum of $2 \mathrm{~h}$ around the reanalysis times, suggests a too strong and vertically too thick monsoon flow as well as an overestimation of the African Easterly Jet and might point to a deficiency of the reanalysis as opposed to one of the pilot balloon measurements. As an example, Fig. 6 shows fields of the difference on the 600-, 700-, and $850-\mathrm{hPa}$ pressure levels for the boreal summer season [JuneAugust (JJA)]. For the central part of sub-Saharan Africa in general, a northerly to northeasterly bias of the reanalysis relative to observations is found for March-May (MAM; not shown) and JJA with a maximum, depending on the season, between 500 and $700 \mathrm{hPa}$, and a westerly to southwesterly bias in all seasons between 850 and $925 \mathrm{hPa}$ (maximum in JJA). The seasonal mean difference reaches values of about $5 \mathrm{~m} \mathrm{~s}^{-1}$ in some regions. More details can be found in A. Stickler et al. (2010, unpublished manuscript).

Analysis of the Dust Bowl droughts. Brönnimann et al. (2009a) analyzed the three-dimensional regional as well as large-scale atmospheric circulation during the Dust Bowl droughts in the 1930s in the U.S. Midwest based on pilot balloon as well as aircraft data from the newly developed dataset. The study found that the Great Plains low-level jet, responsible for the largest part of moisture advection into the region during summer (Rasmusson 1967), was significantly weakened on its eastern flank and was shallower and penetrated less far to the north during the 1930s compared to the much wetter first half of the 1940s.

It is interesting to note that model simulations up to now have failed to reproduce the exact regional structure of the precipitation anomalies; for instance, they also produce a drought in northern Mexico that was not observed (Schubert et al. 2004b; Cook et al. 

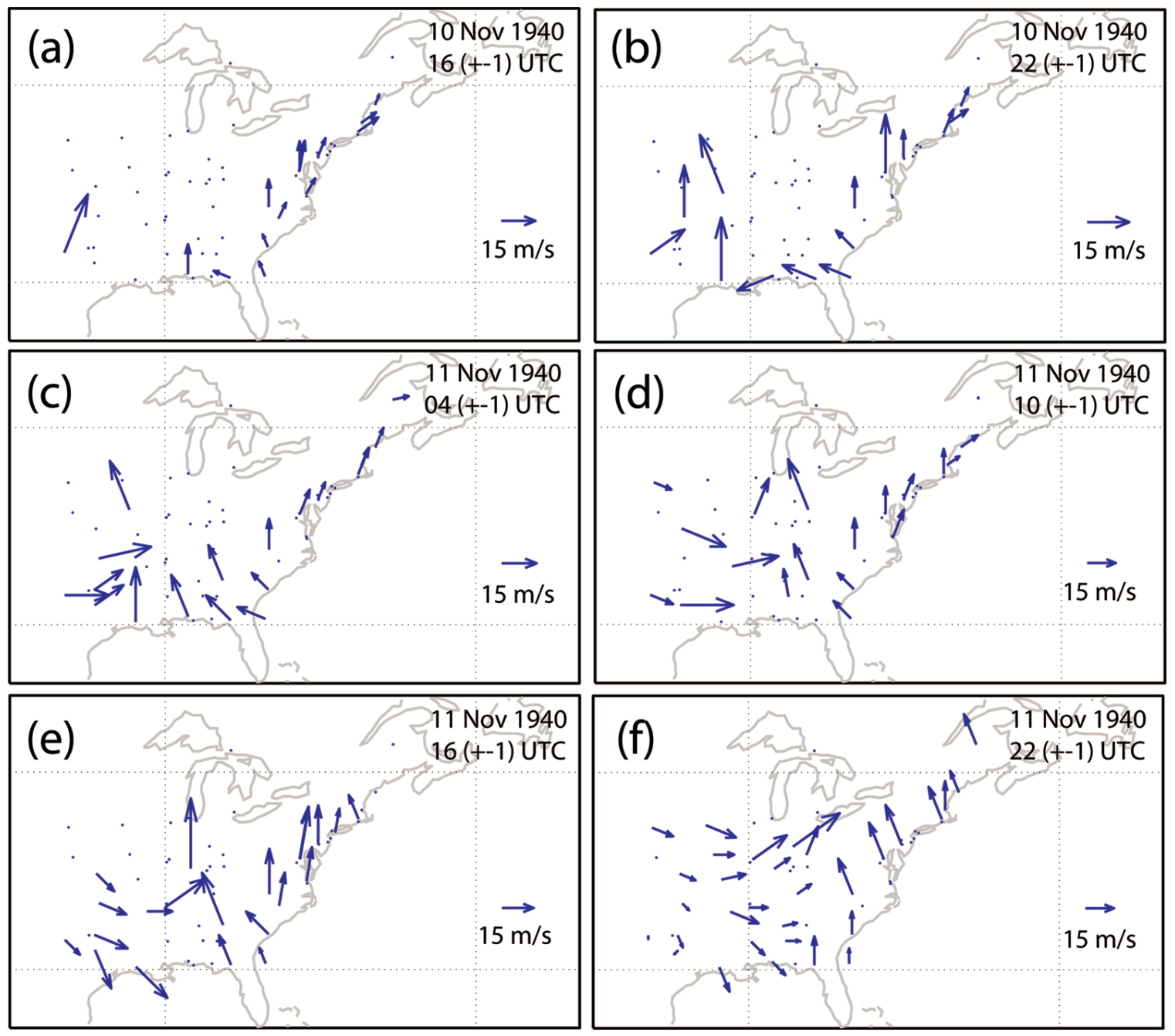

Fig. 7. Wind fields at $1000 \mathrm{~m}$ MSL from pilot balloon measurements for 10 and II Nov 1940, the days of the explosive development of the so-called Armistice Day storm, for the eastern part of North America $\left(30^{\circ}-50^{\circ} \mathrm{N}, 100^{\circ}-65^{\circ} \mathrm{W}\right)$. Wind fields are shown in 6-hourly intervals. Because the ascent times are slightly different at some stations, observations taken inside an interval of $\pm \mathbf{I}$ of the main observation times (0400, 1000, 1600, and 2200 UTC) have been taken into account. Blue dots symbolize stations for which no measurement data are available for the time indicated. The arrow on the right side shows the scale length for $15 \mathrm{~m} \mathrm{~s}^{-1}$.

2008; Seager et al. 2005, 2008). The forcings responsible for the Dust Bowl droughts, as found in model simulations, are expected to proceed through changes in atmospheric circulation (Brönnimann et al. 2009a). The wind data from the CHUAN dataset in the 1930s therefore act as a test case for atmospheric models and might contribute to a further understanding of the exact mechanism of Dust Bowl-like droughts.

The Armistice Day storm of II November 1940. The new dataset can also be used to analyze extreme events like strong midlatitude winter storms, and it has a more general potential for providing insight into significant past events on the synoptic time scale.
As an example, one of the most severe winter storms ever recorded in the central United States was the so-called Armistice Day storm of 11 November 1940. A meteorological description of the storm was given quite early (Knarr 1941), but the respective upper-air data now included in CHUAN were not available in digital form until recently. In Fig. 7 we display wind fields at $1000 \mathrm{~m}$ MSL during the development and culmination phase of the storm. A comparison of the wind fields depicted in Fig. 7 with synoptic weather charts (as provided, e.g., by Knarr 1941) shows generally an excellent agreement: The wind observations at the stations match very well their location with respect to the frontal systems. 
CONCLUSIONS AND OUTLOOK. We have presented the Comprehensive Historical UpperAir Network (CHUAN), a new upper-air dataset that spans the period 1902 to 2007, encompassing the period prior to upper-air-based reanalyses available to date. A monthly mean version can be downloaded from the World Wide Web (see www. historicalupperair.org). CHUAN has been adjusted and evaluated. Further details can be found in Brönnimann (2003b), Ewen et al. (2008a), and Grant et al. (2009a). These newly available data should be useful for analyzing the climate of the first half of the twentieth century by providing quantitative knowledge about a period known to cover some of the most extreme climate events in the twentieth century such as the Dust Bowl droughts in the 1930s (Schubert et al. 2004a,b; Brönnimann et al. 2009a; Cook et al. 2009), the November 1940 Armistice Day storm or the 1939-42 El Niño (Allan et al. 2003; Brönnimann et al. 2004a,b). We have demonstrated that the new upper-air dataset is a valuable tool for the analysis not only of climatological and interannual variability aspects but also of the synoptic development on subdaily timescales. It is hoped that these data may help to eventually deepen our understanding of global climate variability. They might also become important for intended full (i.e., including upper-air information) reanalysis projects going further back in time. Furthermore, the data have already proven highly valuable for the evaluation of surface based reanalyses like the Twentieth-Century Reanalysis project. A similar positive impact can be expected from the evaluation of statistical climate reconstructions and of climate model simulations. Considerable digitization and homogenization work dealing with historical upper-air data is still ongoing (e.g., in the framework of the NOAA-NCDC Climate Data Modernization Program) or planned. In addition to the data themselves, it would be very beneficial if the metadata, helpful to apply corrections in the first place, were more readily available for future quality assessment. All datasets used for the compilation of CHUAN and discussed in this paper will be made available at NCDC, including the single-ascent data.

ACKNOWLEDGMENTS. AS, ANG, TE, TG, and SB were funded by the Swiss National Science Foundation (PP002-102731). GPC was supported by the NOAA Climate Program Office. ERA-40 data were downloaded from the ECMWF server. NCEP-NCAR 50-year reanalysis data were downloaded from the NCAR website. Thanks go to SMHI and NMI for providing large parts of the Scandinavian radiosonde data. We would like to acknowledge COST action ES0601. Rob Allan is supported with funds from the Queensland Climate Change Centre of Excellence (QCCCE) in Australia, together with the joint DECC, Defra, and MoD Integrated Climate Programme (ICP) in the UK-GA01101, CBC/2B/0417_Annex C5.

\section{REFERENCES}

Allan, R. J., C. J. C. Reason, J. A. Lindesay, and T. J. Ansell, 2003: "Protracted" ENSO episodes and their impacts in the Indian Ocean region. Deep-Sea Res. II, 50, 2331-2347.

Brönnimann, S., 2003a: Description of the 1939-1944 upper air data set (UA39_44) version 1.0. Tech. Rep., Lunar and Planetary Laboratory, Univ. of Arizona, Tucson, $40 \mathrm{pp}$.

— 2003b: A historical upper air data set for the 1939-1944 period. Int. J. Climatol., 23, 769-791.

—-, and J. Luterbacher, 2004: Reconstructing Northern Hemisphere upper-level fields during World War II. Climate Dyn., 22, 499-510.

— - _ J. Staehelin, T. M. Svendby, G. Hansen, and T. Svenøe, 2004a: Extreme climate of the global troposphere and stratosphere in 1940-42 related to El Niño. Nature, 431, 971-974.

,,$-- \ldots$, and ——, 2004b: An extreme anomaly in stratospheric ozone over Europe in 1940-42. Geophys. Res. Lett., 31, L08101, doi:10.1029/2004GL019611.

- , A. Stickler, T. Griesser, T. Ewen, A. N. Grant, A. M. Fischer, M. Schraner, T. Peter, E. Rozanov, and T. Ross, 2009a: Exceptional atmospheric circulation during the "Dust Bowl." Geophys. Res. Lett., 36, L08802, doi:10.1029/2009GL037612.

,,,--- A. M. Fischer, A. Grant, T. Ewen, T. Zhou, M. Schraner, E. Rozanov, and T. Peter, 2009b: Variability of large-scale atmospheric circulation indices for the Northern Hemisphere during the past 100 years. Meteor. Z., 18, 379-396.

Compo, G. P., J. S. Whitaker, and P. D. Sardeshmukh, 2006: Feasibility of a 100-year reanalysis using only surface pressure data. Bull. Amer. Meteor. Soc., 87, 175-190.

Cook, B. I., R. L. Miller, and R. Seager, 2008: Dust and sea surface temperature forcing of the 1930s "Dust Bowl” drought. Geophys. Res. Lett., 35, L08710, doi:10.1029/2008GL033486.

—, — and — 2009: Amplification of the North American "Dust Bowl" drought through humaninduced land degradation. Proc. Natl. Acad. Sci., 106, 4997-5001.

Dupigny-Giroux, L. A., T. F. Ross, J. D. Elms, R. Truesdell, and S. R. Doty, 2007: NOAA's Climate Database Modernization Program: Rescuing, 
archiving, and digitizing history. Bull. Amer. Meteor. Soc., 88, 1015-1017.

Durre, I., T. C. Peterson, and R. S. Vose, 2002: Evaluation of the effect of the Luers-Eskridge radiation adjustments on radiosonde temperature homogeneity. $J$. Climate, 15, 1335-1347.

-, R. S. Vose, and D. B. Wuertz, 2006: Overview of the Integrated Global Radiosonde Archive. J. Climate, 19, 53-68.

Eskridge, R. E., O. A. Alduchov, I. V. Chemykh, Z. Panmao, A. C. Polansky, and S. R. Doty, 1995: A Comprehensive Aerological Reference Data Set (CARDS): Rough and systematic errors. Bull. Amer. Meteor. Soc., 76, 1759-1775.

Ewen, T., A. Grant, and S. Brönnimann, 2008a: A monthly upper-air dataset for North America back to 1922 from the Monthly Weather Review. Mon. Wea. Rev., 136, 1792-1805.

—, S. Brönnimann, and J. Annis, 2008b: An extended Pacific-North American index from upper-air historical data back to 1922. J. Climate, 21, 1295-1308.

Grant, A. N., S. Brönnimann, T. Ewen, and A. Nagurny, 2009a: A new look at radiosonde data prior to 1958 . J. Climate, 22, 3232-3247.

,,,--- T. Griesser, and A. Stickler, 2009b: The early twentieth century warm period in the European Arctic. Meteor. Z., 18, 425-432.

Griesser, T., S. Brönnimann, A. Grant, T. Ewen, A. Stickler, and J. Comeaux, 2010: Reconstruction of global monthly upper-level temperature and geopotential height fields back to 1880 . J. Climate, in press.

Hoinka, K. P., 1997: The tropopause: Discovery, definition, and demarcation. Meteor. Z., 6, 281-303.
Kistler, R., and Coauthors, 2001: The NCEP-NCAR 50-Year Reanalysis: Monthly means CD-ROM and documentation. Bull. Amer. Meteor. Soc., 82, 247-268.

Knarr, A. J., 1941: The Midwest storm of November 11, 1940. Mon. Wea. Rev., 69, 169-178.

Overland, J. E., M. C. Spillane, D. B. Percival, M. Wang, and H. O. Mofjeld, 2004: Seasonal and regional variation of pan-Arctic surface air temperature over the instrumental record. J. Climate, 17, 3263-3282.

Polyakov, I. V., R. V. Bekryaev, G. V. Alekseev, U. S. Bhatt, R. L. Colony, M. A. Johnson, A. P. Maskshtas, and D. Walsh, 2003: Variability and trends of air temperature and pressure in the maritime Arctic 1875-2000. J. Climate, 16, 2067-2077.

Rasmusson, E. M., 1967: Atmospheric water vapor transport and the water balance of North America. Part 1: Characteristics of the water vapor flux field. Mon. Wea. Rev., 95, 403- 426.

Schubert, S. D., M. J. Suarez, P. J. Pegion, R. D. Koster, and J. T. Bacmeister, 2004a: On the cause of the 1930s Dust Bowl. Science, 303, 1855-1859.

$-, \ldots, \ldots, \ldots$, and $\_, 2004 \mathrm{~b}$ : Causes of longterm drought in the U.S. Great Plains. J. Climate, 17, 485-503.

Seager, R., Y. Kushnir, C. Herweijer, N. Naik, and J. Velez, 2005: Modeling of tropical forcing of persistent droughts and pluvials over western North America: 1856-2000. J. Climate, 18, 4065-4088.

$\_, \ldots$, M. Ting, M. Cane, N. Naik, and J. Miller, 2008: Would advance knowledge of 1930s SSTs have allowed prediction of the Dust Bowl drought? J. Climate, 21, 3261-3281.

Uppala, S. M., and Coauthors, 2005: The ERA-40 reanalysis. Quart. J. Roy. Meteor. Soc., 131, 2961-3012.

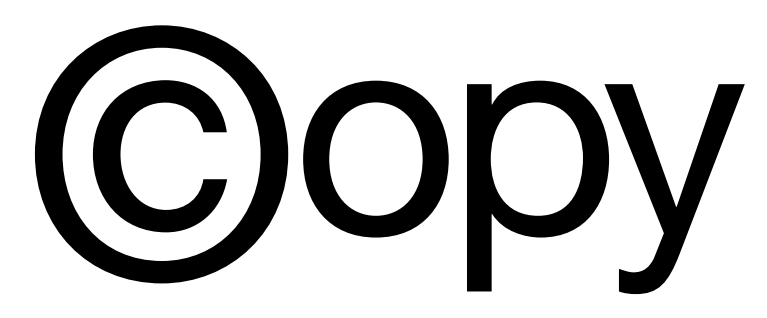

What you're reading is more than just copy. It's also copyrighted. So before you head over to the photocopier, make sure you have permission. Contact the publisher or visit www.copyright.com.

(C) Copyright Clearance Center 


\section{AMERICAN METEOROLOGICAL SOCIETY}

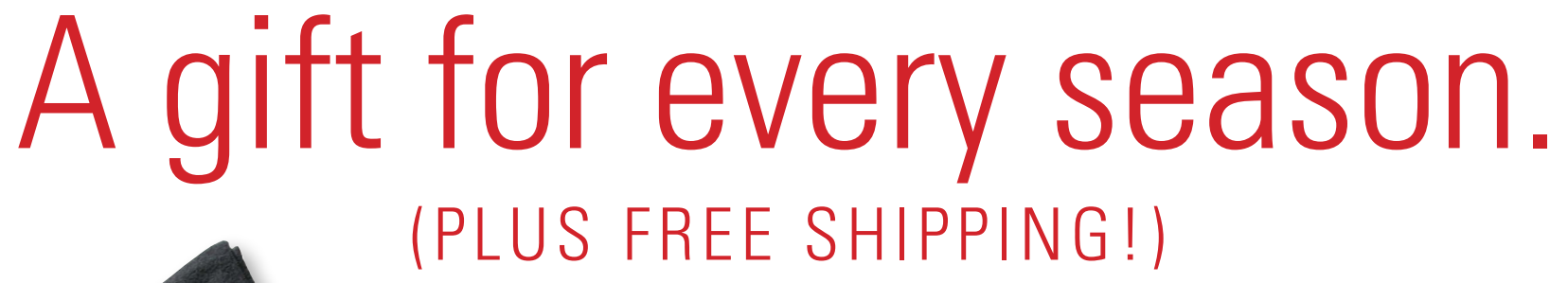

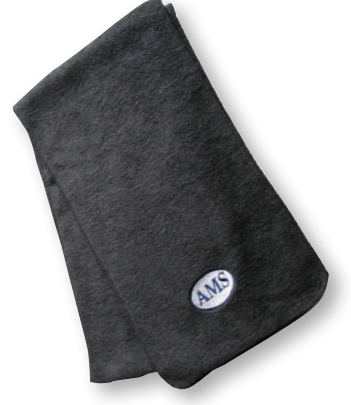

Fleece Scarf COLOR: Charcoal with AMS emblem

Silk Tie with weather symbols

COLORS: Navy with white symbols Burgundy with gold symbols

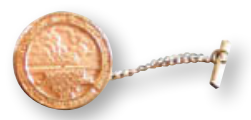

Tie Tack

$\$ 10$

COLOR: Gold

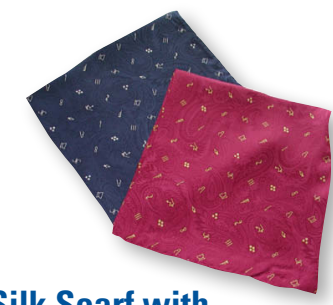

Silk Scarf with

$\$ 17$

COLORS: Navy with white symbols Burgundy with gold symbols
$\$ 17$

$\$ 17$

\section{2}

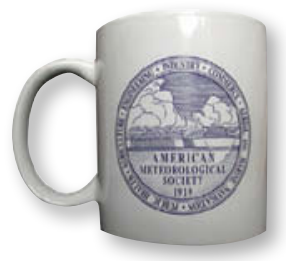

Ceramic Mug

COLORS: Navy with white AMS seal White with navy AMS seal

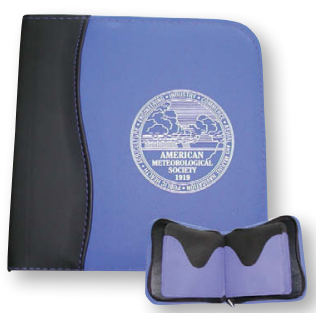

2 Pocket CD Case

$\$ 9$

COLOR: Blue with white AMS seal

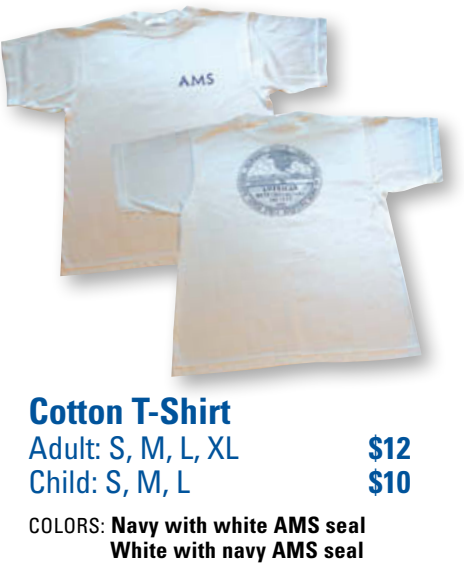

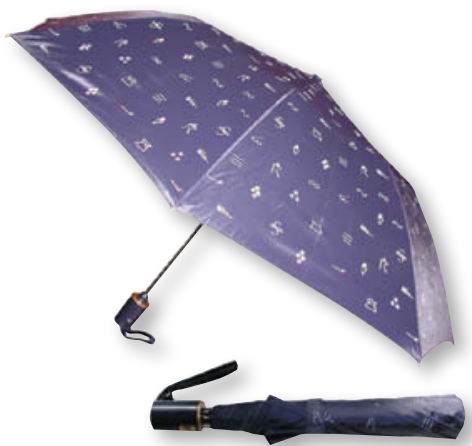

Umbrella with weather symbols $\$ 14$ COLOR: Navy with white symbols

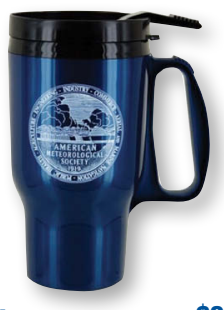

Travel Mug $\$ 8$

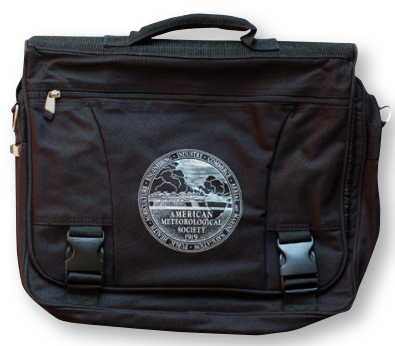

\section{Soft Briefcase}

$\$ 27$

COLOR: Black with white AMS seal DIMENSIONS: 16"L, 12.5"H, 3.75"W (expands to $5^{\prime \prime}$ )

ORDER TODAY! Prepay by check/money order, Visa, MC, or AMEX CALL 617-227-2426 ext. 686 FAX 617-742-8718 mall AMS, 45 Beacon Street, Boston, MA 02108-3693

FOR MORE GIFT IDEAS check out the new AMS Online Bookstore (weather books, biographies, histories, monographs and more) at www.ametsoc.org/amsbookstore.

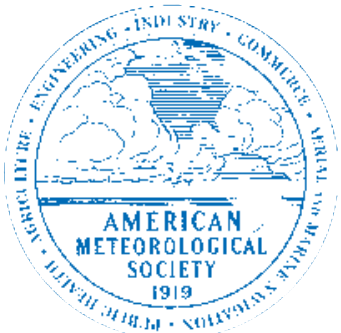

